\title{
Association of liver cirrhosis with the prognosis of patients with intrahepatic cholangiocarcinoma: a SEER-based cohort study
}

Wei Li

Sichuan University

Hong Wu

Sichuan University

Yange Zhang ( $\square$ zhangyangeplastic@126.com )

Sichuan University

Research article

Keywords: Intrahepatic cholangiocarcinoma; Fibrosis score; Prognosis

Posted Date: August 25th, 2020

DOI: https://doi.org/10.21203/rs.3.rs-56371/v1

License: (c) (i) This work is licensed under a Creative Commons Attribution 4.0 International License.

Read Full License 


\section{Abstract \\ Background}

The association of liver cirrhosis with the prognosis of intrahepatic cholangiocarcinoma (ICC) remains controversial. We aimed to evaluate the relationship between liver cirrhosis (fibrosis score) and the longterm prognosis of patients with ICC.

\section{Methods}

SEER 18 registry from 2004 to 2015 was queried for this study. Propensity score matching (PSM) was performed to eliminate possible bias. In addition, multivariable analysis was utilized to adjust for potential confounders. The interaction test was performed to explore the impact of each stratified factor on the relationship between FS and patient survival. Overall survival (OS) and disease-specific survival (DSS) were the major endpoints.

\section{Results}

During the study period, 359 patients (66.5\%) with lower fibrosis score (LFS; F0-4) and 181 patients (33.5\%) with higher fibrosis score (HFS; F5-6) were enrolled. In the multivariable adjusted cohort (OS: $\mathrm{n}=$ 540; DSS: $n=417)$, patients with HFS had worse OS (HR, 1.43; $95 \% \mathrm{Cl}, 1.10$ to $1.85 ; \mathrm{P}=0.007)$ and DSS

(HR, $1.46 ; 95 \% \mathrm{Cl}, 1.08$ to $1.97 ; \mathrm{P}=0.013$ ) compared to patients with LFS. In the propensity-matched cohort, patients with HFS still had worse OS $(H R, 1.50 ; 95 \% \mathrm{Cl}, 1.08$ to $2.09 ; \mathrm{P}=0.016)$ and DSS $(\mathrm{HR}, 1.54$; $95 \% \mathrm{Cl}, 1.05$ to $2.26 ; \mathrm{P}=0.026$ ) compared to patients with LFS. In multivariable analyses stratified by clinicopathologic features, patients with HFS were found to have significantly worse OS and DSS compared to those with LFS across all the subgroups.

\section{Conclusion}

Our outcomes indicated that fibrosis score is an independent risk factor for both overall and tumorspecific survival of ICC patients.

\section{Background}

Intrahepatic cholangiocarcinoma (ICC), the second most common primary liver tumor, shows increasing incidence rates over the past decades worldwide.[1] Liver resection (LR) is the mainstay treatment with curative intent for ICC and is associated with improved long-term survival in selected patients.[1-4] However, the prognosis after LR for ICC remains poor, and risk factors related to survival after LR have not been clearly elucidated. [5-8] For patients with hepatocellular carcinoma (HCC), liver cirrhosis (usually resulted from hepatitis $\mathrm{B}$ or $\mathrm{C}$ viral infection) has been shown to be one of the risk factors associated with 
poor prognosis after LR.[9] However, several studies showed controversial outcomes about the exact relationship of liver cirrhosis with the prognosis of ICC after LR.[10-12]

In the present study, utilizing the Surveillance, Epidemiology, and End Results (SEER) database, we aimed to explore the independent relationship between liver cirrhosis (fibrosis score) and the long-term prognosis of patients with ICC receiving surgical or non-surgical treatment.

\section{Patients And Methods}

\section{Study population}

SEER 18 registry from 2004 to 2015 was queried for this study. The National Cancer Institute's SEER program routinely collects the high-quality demographic, clinicopathologic, and follow-up information from 18 cancer registries. (seer.cancer.gov/about/overview.html). Patients with a diagnosis of ICC from 2004 to 2015 within the SEER database were identified by the International Classification of Diseases for Oncology, 3rd edition (ICD-0-3) site code C22.1 and histologic type codes 8160 and $8140(n=8171)$. The detailed inclusion and exclusion criteria was shown in Fig. 1. A total of 540 patients with ICC (stage IIII; AJCC, 6th ) matching the specified eligibility criteria were included in the multivariable analyses. The degree of fibrosis was scored according to the definition of Ishak et al, where Ishak 0-2 was no or minimal fibrosis; Ishak 3-4, incomplete bridging fibrosis; and Ishak 5-6, complete bridging fibrosis and nodules. In the SEER database, fibrosis score (FS) has been divided into F0-4 and F5-6, respectively. The SEER codes for ICC treatment were as follows: LR: $20-25,30,36,37,50,51$, and 52; local tumor destruction (LTD): 10-17; liver transplantation (LT): 61. LTD included photodynamic therapy, electrocautery, fulguration, cryosurgery, laser, percutaneous ethanol injection, heat-radiofrequency ablation or other. This study does not need an ethic approval, because the data of SEER is public available.

\section{Statistical analysis}

The primary endpoint in this study was overall survival (OS), defined as the period from the date of diagnosis to death of any cause. Disease-specific survival (DSS) was a secondary endpoint, which was defined as the interval from diagnosis to death from ICC. Categorical and continuous data were compared by utilizing the $\chi 2$ test and the Student $t$ test, respectively. The survival curves were determined by the Kaplan-Meier method and differences between groups were compared by log-rank test. Multivariable Cox proportional hazards regression models were used to analyze risk factors for survival outcomes. The interaction test was performed to explore the impact of each stratified factor on the relationship between FS and patient survival. $P$ value for interaction less than 0.05 means interaction exists between that factor and the relationship.

Propensity score matching (PSM) was performed on the variables of age, race, sex, marriage status, year of diagnosis, tumor grade, treatment methods, lymph node status and AJCC-TNM stage. Patients were 
matched with the closest estimated propensity score within 0.01 of the standard deviation of the logittransformed propensity score. After PSM selection, a new cohort including two comparable groups were obtained and compared by univariable Cox regression. $P$ value less than 0.05 was deemed statistically significant. All statistical analyses were performed by R (http://www.R-project.org) and EmpowerStats software (www.empowerstats.com, X\&Y solutions, Inc. Boston MA).

\section{Results}

\section{Study population}

During the study period, 540 patients presenting with ICC who had been treated with surgery or nonsurgery were enrolled. Of these, 359 patients (66.5\%) had lower fibrosis score (LFS; F0-4) and 181 patients (33.5\%) with higher fibrosis score (HFS; F5-6). The characteristics of the patients with ICC are shown in Table 1. The mean age of patients with LFS and HFS was 65.0 and 63.6 years, respectively. There were significant differences between the two groups, including sex $(P<0.001)$, marriage status $(P=$ $0.035)$, race $(P<0.001)$, treatment modality $(P<0.001)$ and AJCC-TNM stage $(P=0.016)$. With regard to age $(P=0.170)$, insurance $(P=0.277)$, tumor size $(P=0.331)$, lymph node status $(P=0.435)$, tumor differentiation $(P=0.053)$ and year of diagnosis $(P=0.446)$, no significant differences were found.

\section{Multivariable analyses}

A total of 540 patients with available prognostic data were included in survival analyses. In the total cohort, the mean OS times for patients with LFS and HFS were 33.1 months and 25.3 months, respectively. The mean DSS times for patients with LFS and HFS were 33.4 and 26.7 months, respectively. Overall, patients with LFS had longer OS $(P=0.001)$ and $D S S(P=0.017)$ compared to patients with HFS (Fig. 2A and 2B).

As shown in Table 2, in the multivariable adjusted cohort (OS: $n=540$; DSS: $n=417$ ), after adjusting potential confounding factors, patients with HFS had worse OS (HR, 1.43; $95 \% \mathrm{Cl}, 1.10$ to $1.85 ; \mathrm{P}=0.007)$ and DSS $(\mathrm{HR}, 1.46 ; 95 \% \mathrm{Cl}, 1.08$ to $1.97 ; \mathrm{P}=0.013)$ compared to patients with LFS.

\section{Long-term outcomes in PSM-adjusted population}

As shown in Table 1, in the matched cohort, the potential prognostic variables became well-balanced for most baseline characteristics. In the PSM cohort, patients with HFS showed worse OS $(P=0.014)$ and DSS $(P=0.022)$ compared to patients with LFS (Fig. 2C and 2D). In the propensity-matched cohort, the univariable analysis showed that patients with HFS still had worse OS $(\mathrm{HR}, 1.50 ; 95 \% \mathrm{Cl}, 1.08$ to $2.09 ; \mathrm{P}=$ $0.016)$ and $\mathrm{DSS}(\mathrm{HR}, 1.54 ; 95 \% \mathrm{Cl}, 1.05$ to $2.26 ; \mathrm{P}=0.026)$ compared to patients with LFS (Table 2 ).

\section{Stratified Analyses}

In the total cohort, in multivariable analyses stratified by clinicopathologic features (Fig. 3 and Fig. 4), patients with HFS were found to have significantly worse OS and DSS compared with those with LFS 
across all the subgroups (all P values for interaction $>0.05$ ).

\section{Discussion}

In the present study, by utilizing conventional multivariable analyses and PSM methods, we demonstrated that patients with patients with F5-6 fibrosis had significantly worse long-term survival than patients with F0-4 fibrosis. In addition, the role of FS in the survival of ICC patients was consistent across all subgroups. Several publications have explored the clinical significance of liver cirrhosis for prognosis in patients with ICC after hepatectomy.[10-12] Actually, due to the advanced cirrhosis, a large proportion of patients (approximately 65\%) could not be treated with surgery. In this study, we enrolled patients with ICC receiving both surgical (including LR, LT and LTD) and non-surgical treatment to reach more representative conclusions. Additionally, we utilized tumor-specific survival as a major endpoint and found that patients with F5-6 fibrosis still had a worse survival.

Liver cirrhosis have been demonstrated to be a risk factor for long-term survival in patients with HCC.[9, 13] However, owing to the limited number of studies, data related to survival results and prognostic factors of cirrhotic ICC is still insufficient. Recently, Jeong et al. found that the presence of cirrhosis did not significantly influence the long-term prognosis of patients with ICC.[10] However, this study did not provide a convincing evidence due to the limited sample size (included only 106 resected patients with ICC). Study of Li et al. highlighted that cirrhosis was an independent factor associated with poor prognosis in patients with ICC receiving surgery,[11] while they did not perform stratified analyses based on some significant factors such as tumor stage, tumor size and lymph lode status. In addition, they only used OS as the endpoint without DSS.

Liver cirrhosis have been shown to be a risk factor for early tumor recurrence in patients with HCC, which is likely because of multicentric de novo carcinogenesis in the remnant part of the liver.[14] In patients with ICC, the prognostic differences between different FS groups may be attributable to the same reason. In addition, difference in treatment strategies for recurrent tumor may also account for differences in long-term survivals and patients with advanced cirrhosis had less chance for reoperations.[15] However, further studies are needed to explore the mechanisms related to the prognostic differences.

The present study had several limitations. First, liver function, performance status, presence of comorbidities are also significant factors associated with long-term survival in ICC patients. However, the SEER database does not provide these data, thus we cannot evaluate the influence of these risk factors in multivariable analyses. Second, details on the etiology of ICC were extremely limited and we could not know the causes of liver cirrhosis of the included patents (such as the proportion of HBV or HCV infection). Third, we cannot acquire the data about pre- or post-operative treatment (such as transcatheter arterial chemoembolization), thus the influence of adjuvant treatments was not considered in the analytic process. Fourth, the findings of the current study should be interpreted cautiously because a number of patients were excluded from our main analyses due to having an unknown covariates in the SEER database. 
In conclusion, our outcomes indicated that FS 0-4 patients had an overall and disease-specific survival benefit for ICC patients. ICC patients with cirrhosis should be followed-up carefully after treatment. In addition, further studies are still needed to uncover the mechanisms related to the prognostic differences between HFS and LFS groups.

\section{Abbreviations}

ICC: Intrahepatic cholangiocarcinoma LR:Liver resection HCC:Hepatocellular carcinoma SEER:Surveillance, Epidemiology, and End Results FS:Fibrosis score LTD:local tumor destruction LT:Liver transplantation OS:overall survival DSS:Disease-specific survival

\section{Declarations}

Acknowledgements: None.

\section{Author contributions:}

Wu H proposed the study; Li W and Zhang YG performed the research and wrote the first draft; Li W collected and analyzed the data; $\mathrm{Wu} \mathrm{H}$ is the guarantor; all authors contributed to the design and interpretation of the study and to further drafts, and have read and approved the final version to be published.

\section{Ethics approval:}

This study is in accordance with the Declaration of Helsinki and has been approved by the Institutional Review Board at the West China Hospital.

\section{Consent for publication:}

Not applicable

\section{Competing interests:}

The authors declare that they have no competing interests.

Funding: None.

\section{Availability of data and material:}

All primary data is available by sending email to: 13881958922@163.com

\section{References}


1. Rizvi S, Khan SA, Hallemeier CL, Kelley RK, Gores GJ. Cholangiocarcinoma - evolving concepts and therapeutic strategies. Nature reviews Clinical oncology. 2018;15(2):95-111.

2. Fu Y, Yang W, Wu W, Yan K, Xing BC, Chen MH. Radiofrequency ablation in the management of unresectable intrahepatic cholangiocarcinoma. Journal of vascular interventional radiology: JVIR. 2012;23(5):642-9.

3. Kolarich AR, Shah JL, George TJ Jr, Hughes SJ, Shaw CM, Geller BS, Grajo JR. Non-surgical management of patients with intrahepatic cholangiocarcinoma in the United States, 2004-2015: an NCDB analysis. Journal of gastrointestinal oncology. 2018;9(3):536-45.

4. Kuhlmann JB, Blum HE. Locoregional therapy for cholangiocarcinoma. Current opinion in gastroenterology. 2013;29(3):324-8.

5. Beetz O, Klein M, Schrem H, Gwiasda J, Vondran FWR, Oldhafer F, Cammann S, Klempnauer J, Oldhafer KJ, Kleine M. Relevant prognostic factors influencing outcome of patients after surgical resection of distal cholangiocarcinoma. 2018, 18(1):56.

6. Gao Y, Feng H, Warner E, An M, Jia J, Chen S, Fang M, Ji J, Gu X, Gao C, et al. Preoperative Risk Score and Prediction of Long-Term Outcomes after Hepatectomy for Intrahepatic Cholangiocarcinoma. Cancer medicine. 2018;226(4):393-403.

7. Wang M. A nomogram incorporating six easily obtained parameters to discriminate intrahepatic cholangiocarcinoma and hepatocellular carcinoma. BMC Surg. 2018;7(3):646-54.

8. Zhang XF, Beal EW, Bagante F, Chakedis J, Weiss M, Popescu I, Marques HP, Aldrighetti L, Maithel SK, Pulitano $C$, et al: Early versus late recurrence of intrahepatic cholangiocarcinoma after resection with curative intent. 2018, 105(7):848-856.

9. Kamarajah SK: Fibrosis score impacts survival following resection for hepatocellular carcinoma (HCC): A Surveillance, End Results and Epidemiology (SEER) database analysis. Asian journal of surgery 2018.

10. Jeong S, Gao L, Tong Y, Xia L, Xu N, Sha M, Zhang J, Kong X, Gu J. Prognostic Impact of Cirrhosis in Patients with Intrahepatic Cholangiocarcinoma following Hepatic Resection. 2017, 2017:6543423.

11. Li YY, Li H, Lv P, Liu G, Li XR, Tian BN, Chen DJ. Prognostic value of cirrhosis for intrahepatic cholangiocarcinoma after surgical treatment. Journal of gastrointestinal surgery: official journal of the Society for Surgery of the Alimentary Tract. 2011;15(4):608-13.

12. Yap AQ, Chen CL, Yong CC, Kuo FY, Wang SH, Lin CC, Liu YW, Lin TL, Li WF, Millan CA, et al. Clinicopathological factors impact the survival outcome following the resection of combined hepatocellular carcinoma and cholangiocarcinoma. Surg Oncol. 2013;22(1):55-60.

13. Conti F, Buonfiglioli F, Scuteri A, Crespi C, Bolondi L, Caraceni P, Foschi FG, Lenzi M, Mazzella G, Verucchi G, et al. Early occurrence and recurrence of hepatocellular carcinoma in HCV-related cirrhosis treated with direct-acting antivirals. Journal of hepatology. 2016;65(4):727-33.

14. Sasaki Y, Imaoka S, Masutani S, Ohashi I, Ishikawa O, Koyama H, Iwanaga T. Influence of coexisting cirrhosis on long-term prognosis after surgery in patients with hepatocellular carcinoma. Surgery. 1992;112(3):515-21. 
15. Si A, Li J, Xing X, Lei Z, Xia Y, Yan Z, Wang K, Shi L, Shen F. Effectiveness of repeat hepatic resection for patients with recurrent intrahepatic cholangiocarcinoma: Factors associated with long-term outcomes. Surgery. 2017;161(4):897-908.

\section{Tables}


Table 1. Baseline demographic and clinical characteristics for patients with intrahepatic cholangiocarcinoma.

\begin{tabular}{|c|c|c|c|c|c|c|}
\hline & \multicolumn{3}{|l|}{ Before PSM } & \multicolumn{3}{|l|}{ After PSM } \\
\hline & $\begin{array}{l}\operatorname{LFS}(n= \\
359)\end{array}$ & $\begin{array}{l}\text { HFS }(n= \\
181)\end{array}$ & $\begin{array}{l}\mathrm{P} \\
\text { value }\end{array}$ & $\begin{array}{l}\text { LFS }(n= \\
168)\end{array}$ & $\begin{array}{l}\text { HFS }(n= \\
84)\end{array}$ & $\begin{array}{l}\mathrm{P} \\
\text { value }\end{array}$ \\
\hline Age (years) & $65.0 \pm 12.1$ & $63.6 \pm 9.6$ & 0.170 & $65.0 \pm 12.0$ & $\begin{array}{l}64.0 \pm \\
10.1\end{array}$ & 0.509 \\
\hline Sex & & & $<0.001$ & & & 0.894 \\
\hline Female & $\begin{array}{l}187 \\
(52.1 \%)\end{array}$ & $66(36.5 \%)$ & & 87 (51.8\%) & $45(53.6 \%)$ & \\
\hline Male & $\begin{array}{l}172 \\
(47.9 \%)\end{array}$ & $\begin{array}{l}115 \\
(63.5 \%)\end{array}$ & & $81(48.2 \%)$ & $39(46.4 \%)$ & \\
\hline Marriage status & & & 0.035 & & & 0.346 \\
\hline Married & $\begin{array}{l}234 \\
(67.8 \%)\end{array}$ & $\begin{array}{l}100 \\
(56.8 \%)\end{array}$ & & $\begin{array}{l}124 \\
(73.8 \%)\end{array}$ & $57(67.9 \%)$ & \\
\hline Divorced & $73(21.2 \%)$ & $46(26.1 \%)$ & & $31(18.5 \%)$ & $22(26.2 \%)$ & \\
\hline Separated/single & $38(11.0 \%)$ & $30(17.0 \%)$ & & $13(7.7 \%)$ & $5(6 \%)$ & \\
\hline Insurance & & & 0.277 & & & 0.306 \\
\hline Yes & $\begin{array}{l}323 \\
(97.9 \%)\end{array}$ & $\begin{array}{l}166 \\
(99.4 \%)\end{array}$ & & $\begin{array}{l}149 \\
(97.4 \%)\end{array}$ & $\begin{array}{l}74 \\
(100.0 \%)\end{array}$ & \\
\hline No & $7(2.1 \%)$ & $1(0.6 \%)$ & & $4(2.6 \%)$ & $0(0.0 \%)$ & \\
\hline Race & & & $<0.001$ & & & 0.762 \\
\hline White & $\begin{array}{l}264 \\
(73.5 \%)\end{array}$ & $\begin{array}{l}152 \\
(84.0 \%)\end{array}$ & & $136(81 \%)$ & $67(79.8 \%)$ & \\
\hline Black & $20(5.6 \%)$ & $14(7.7 \%)$ & & $10(6 \%)$ & $7(8.3 \%)$ & \\
\hline Other & $75(20.9 \%)$ & $15(8.3 \%)$ & & $22(13.1 \%)$ & $10(11.9 \%)$ & \\
\hline \multicolumn{7}{|l|}{ Unknown } \\
\hline Tumor size (mm) & $64.7 \pm 37.5$ & $61.4 \pm 35.2$ & 0.331 & $63.4 \pm 37.5$ & $\begin{array}{l}64.9 \pm \\
39.3\end{array}$ & 0.762 \\
\hline $\begin{array}{l}\text { Treatment } \\
\text { modality }\end{array}$ & & & $<0.001$ & & & 0.151 \\
\hline Non-surgical & $\begin{array}{l}206 \\
(57.4 \%)\end{array}$ & $\begin{array}{l}122 \\
(67.4 \%)\end{array}$ & & $97(57.7 \%)$ & $54(64.3 \%)$ & \\
\hline Liver resection & $\begin{array}{l}134 \\
(37.3 \%)\end{array}$ & $35(19.3 \%)$ & & $61(36.3 \%)$ & $22(26.2 \%)$ & \\
\hline
\end{tabular}




\begin{tabular}{|c|c|c|c|c|c|c|}
\hline Liver transplant & $2(0.6 \%)$ & $8(4.4 \%)$ & & $1(0.6 \%)$ & $3(3.6 \%)$ & \\
\hline $\begin{array}{l}\text { Locoregional } \\
\text { therapy }\end{array}$ & $17(4.7 \%)$ & $16(8.8 \%)$ & & $9(5.4 \%)$ & $5(6 \%)$ & \\
\hline $\begin{array}{l}\text { Lymph node } \\
\text { status }\end{array}$ & & & 0.435 & & & 0.868 \\
\hline Negative & $\begin{array}{l}267 \\
(74.4 \%)\end{array}$ & $\begin{array}{l}134 \\
(74.0 \%)\end{array}$ & & $\begin{array}{l}125 \\
(74.4 \%)\end{array}$ & $65(77.4 \%)$ & \\
\hline Positive & $86(24.0 \%)$ & $41(22.7 \%)$ & & $38(22.6 \%)$ & $17(20.2 \%)$ & \\
\hline AJCC-TNM stage & & & 0.016 & & & 0.041 \\
\hline I & $\begin{array}{l}124 \\
(34.5 \%)\end{array}$ & $64(35.4 \%)$ & & $63(37.5 \%)$ & $33(39.3 \%)$ & \\
\hline II & $43(12.0 \%)$ & 19 (10.5\%) & & $22(13.1 \%)$ & $11(13.1 \%)$ & \\
\hline III & $\begin{array}{l}114 \\
(31.8 \%)\end{array}$ & $39(21.5 \%)$ & & $52(31 \%)$ & $14(16.7 \%)$ & \\
\hline IV & $78(21.7 \%)$ & $59(32.6 \%)$ & & $31(18.5 \%)$ & $26(31 \%)$ & \\
\hline $\begin{array}{l}\text { Tumor } \\
\text { differentiation }\end{array}$ & & & 0.053 & & & 0.828 \\
\hline I & $29(8.1 \%)$ & $9(5.0 \%)$ & & $10(6 \%)$ & 7 (8.3\%) & \\
\hline II & $\begin{array}{l}120 \\
(33.4 \%)\end{array}$ & $47(26.0 \%)$ & & $60(35.7 \%)$ & $29(34.5 \%)$ & \\
\hline III & $81(22.6 \%)$ & $43(23.8 \%)$ & & $44(26.2 \%)$ & $22(26.2 \%)$ & \\
\hline IV & $4(1.1 \%)$ & $0(0.0 \%)$ & & $2(1.2 \%)$ & $0(0 \%)$ & \\
\hline Year of diagnosis & & & 0.446 & & & 0.679 \\
\hline 2004-2009 & $90(25.1 \%)$ & $40(22.1 \%)$ & & $40(23.8 \%)$ & $22(26.2 \%)$ & \\
\hline $2010-2015$ & $\begin{array}{l}269 \\
(74.9 \%)\end{array}$ & $\begin{array}{l}141 \\
(77.9 \%)\end{array}$ & & $\begin{array}{l}128 \\
(76.2 \%)\end{array}$ & $62(73.8 \%)$ & \\
\hline
\end{tabular}


Table 2. Association of fibrosis score with patient survival.

\begin{tabular}{|c|c|c|c|c|c|c|}
\hline & \multicolumn{3}{|l|}{ OS } & \multicolumn{3}{|l|}{ DSS } \\
\hline & Number & $\mathrm{HR}(95 \% \mathrm{Cl}) \dagger$ & $\begin{array}{l}\mathrm{P} \\
\text { value }\end{array}$ & Number & $\begin{array}{l}\mathrm{HR} \\
(95 \% \mathrm{Cl}) \dagger\end{array}$ & $\begin{array}{l}P \\
\text { value }\end{array}$ \\
\hline Non-adjusted & 540 & $\begin{array}{l}1.42(1.14 \\
1.77)\end{array}$ & 0.002 & 417 & $\begin{array}{l}1.35(1.05 \\
1.73)\end{array}$ & 0.020 \\
\hline $\begin{array}{l}\text { Multivariable adjusted } \\
\text { model* }^{\star}\end{array}$ & 540 & $\begin{array}{l}1.43(1.10 \\
1.85)\end{array}$ & 0.007 & 417 & $\begin{array}{l}1.46(1.08, \\
1.97)\end{array}$ & 0.013 \\
\hline $\begin{array}{l}\text { Matched on propensity } \\
\text { score }^{\star \star}\end{array}$ & 252 & $\begin{array}{l}1.50(1.08 \\
2.09)\end{array}$ & 0.016 & 195 & $\begin{array}{l}1.54(1.05 \\
2.26)\end{array}$ & 0.026 \\
\hline \multicolumn{7}{|c|}{$\begin{array}{l}\text { Data are shown as HR }(95 \% \mathrm{Cl}) \mathrm{P} \text { value. *Adjusted model was adjusted for: age, race, sex, } \\
\text { marriage status, year of diagnosis, tumor grade, treatment methods, lymph node status and } \\
\text { AJCC-TNM stage. **PSM model was based on the following variables: age, race, sex, marriage } \\
\text { status, year of diagnosis, tumor grade, treatment methods, lymph node status and AJCC-TNM } \\
\text { stage. OS, overall survival; DSS, disease-specific survival. }\end{array}$} \\
\hline
\end{tabular}

\section{Figures}


SEER Research Database 2004-2015

Intrahepatic cholangiocarcinoma

(ICD-O-3 site code: C22.1; ICD-O-3

histologic type: 8160,8140$)(n=8171)$

\section{Unknown FS $(n=7367)$}

\section{Known FS $(n=804)$}

\section{Unknown overall survival or survival month $<1(n=110)$}

Patients in the final non-adjusted regression analytic set $(n=694)$

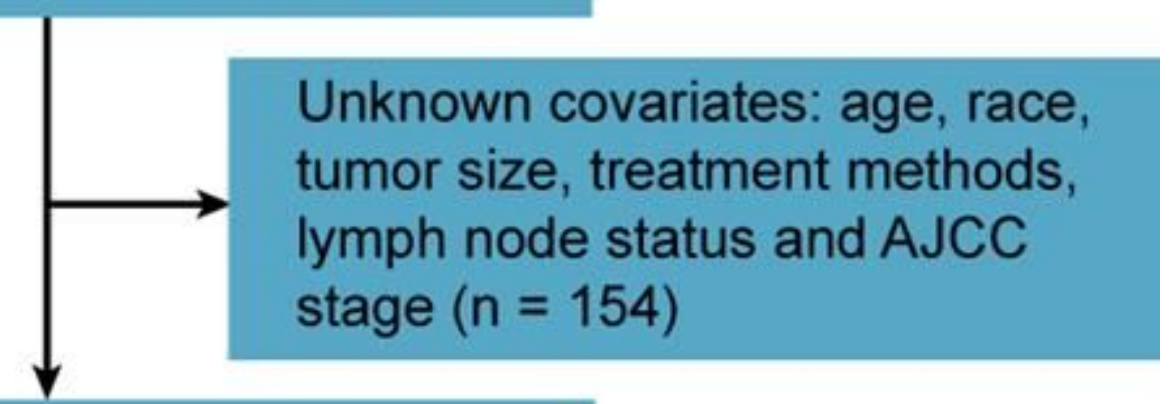

Number of patients in multivariable adjusted population $(n=540)$

\section{Figure 1}

Flowchart representing selection process of patients included in this study. SEER, Surveillance, Epidemiology, and End Results; FS, fibrosis score; AJCC, American Joint Committee on Cancer. 
A

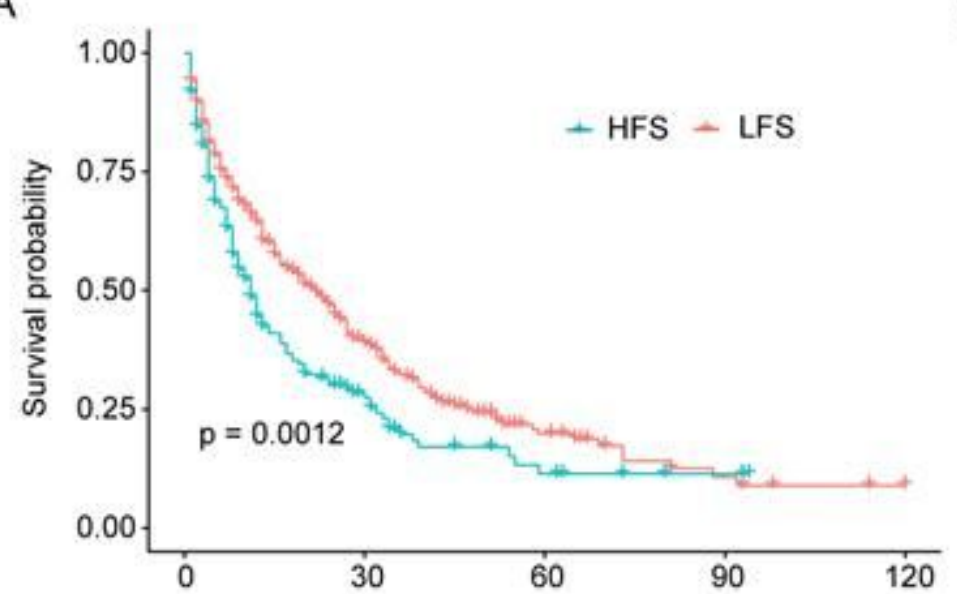

Number at risk

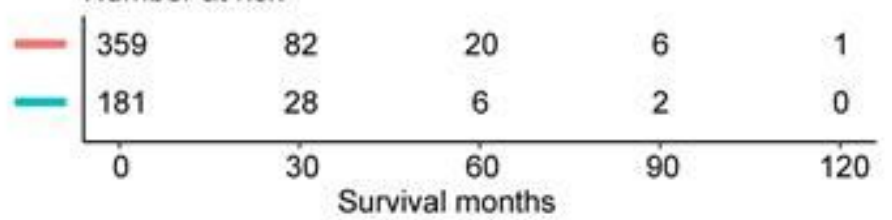

C

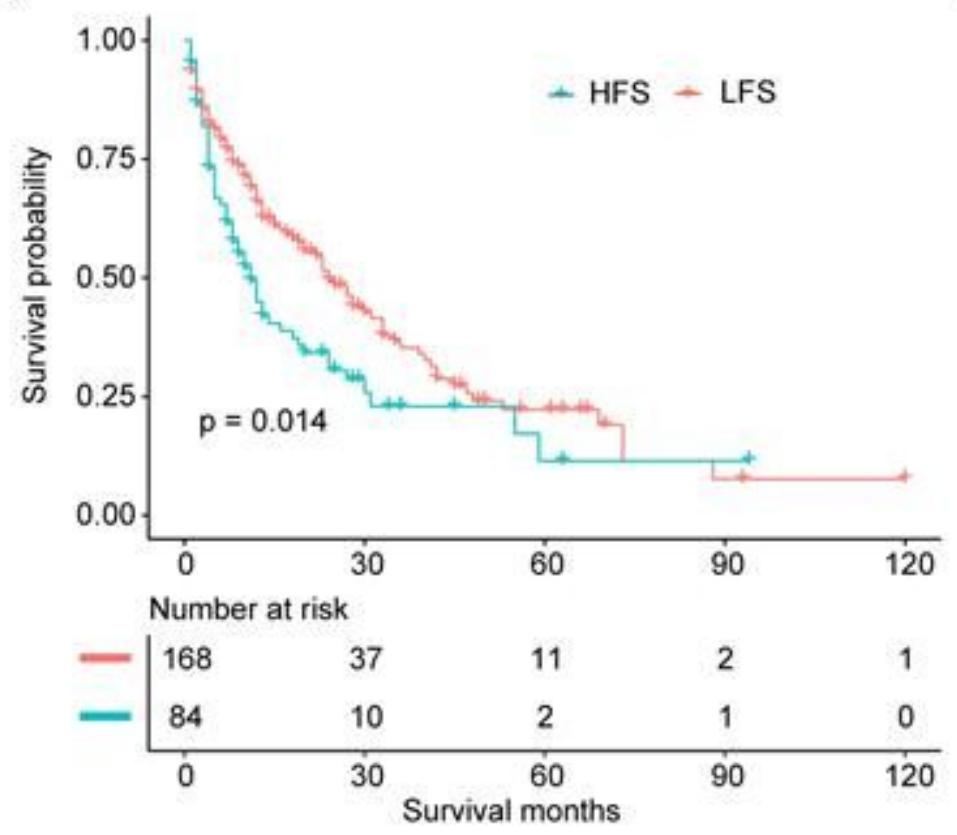

B

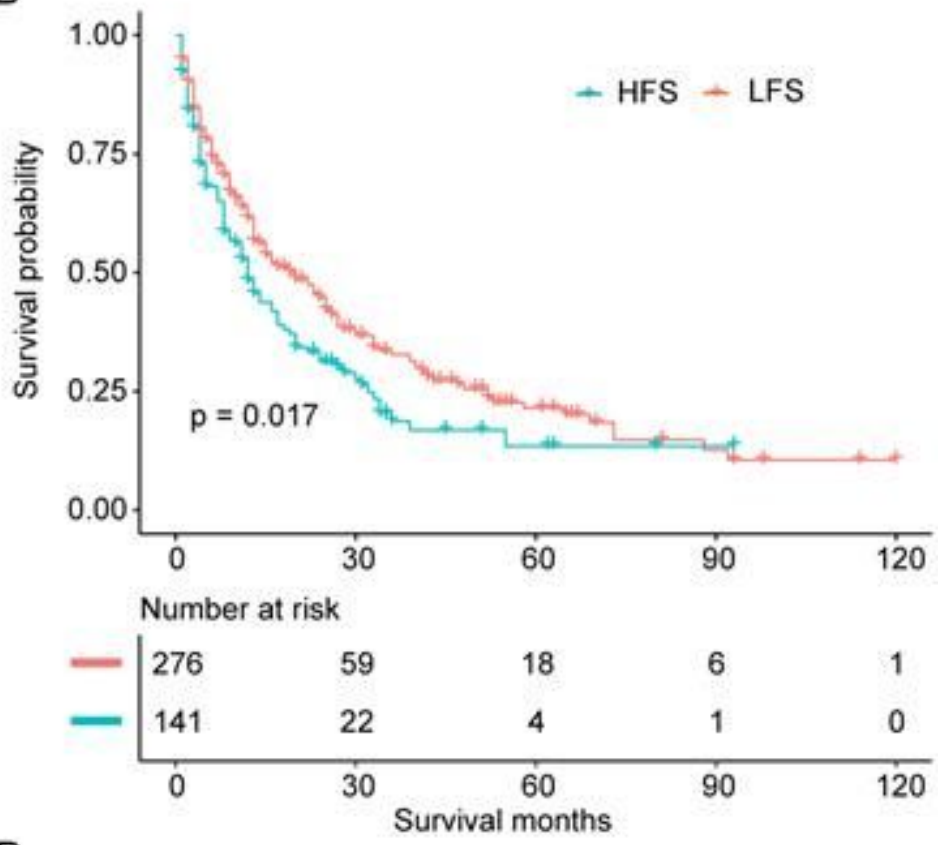

D

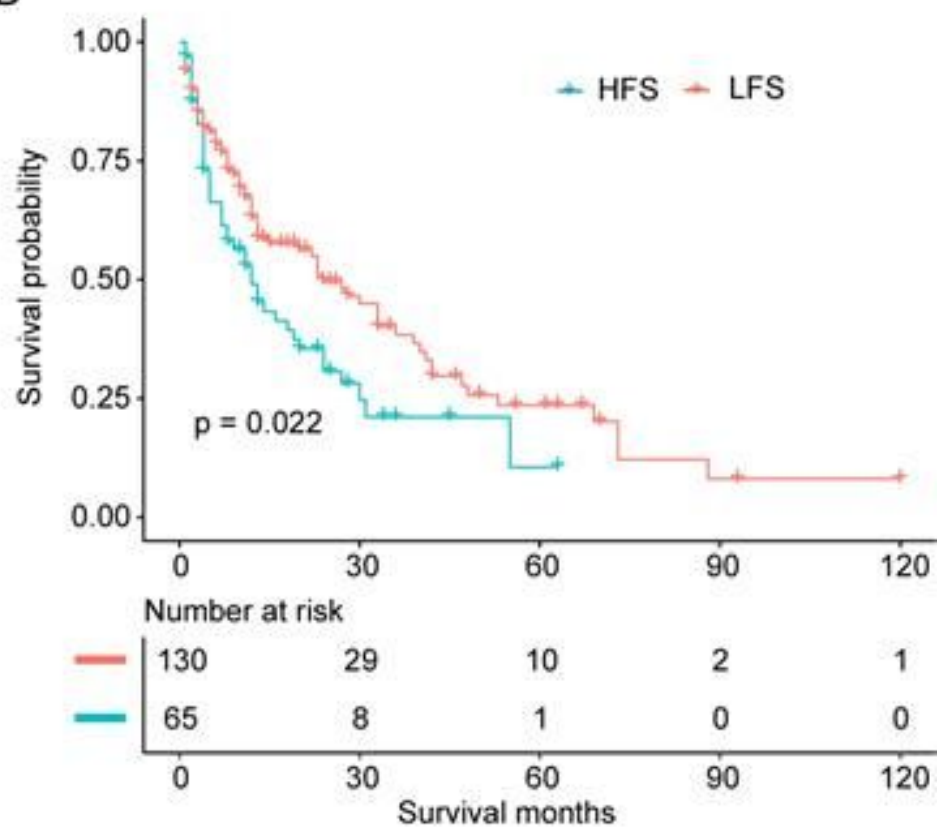

\section{Figure 2}

A: Overall survival analysis for patients with LFS and HFS in non-adjusted population. B: Disease-specific survival analysis for patients with LFS and HFS in non-adjusted population. C: Overall survival analysis for patients with LFS and HFS in propensity score matched population. D: Disease-specific survival analysis for patients with LFS and HFS in propensity score matched population. 
Subgroups

All

Sex

Female

Male

Age, years

$>=45,<60$

$>=60$

\section{Race}

White

Non-White

Tumor size, $\mathrm{mm}$

$<30$

$>=30,<50$

$>=50,<70$

$>=70$

Treatment modality

Non-surgical

Liver resection

Lynph node status

Negative

Positive

AJCC-TNM stage

$$
\text { I-II }
$$

III-IV

Year of diagnosis 2004-2009

2010-2015
No.

540

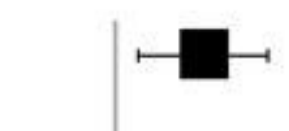

HR

$95 \% \mathrm{Cl}$

P-Interaction

$1.43 \quad(1.10,1.85)$

0.121

$1.67 \quad(1.13,2.48)$

$1.08 \quad(0.78,1.50)$

0.577

$1.13 \quad(0.67,1.91)$

$1.35 \quad(0.99,1.83)$

0.710

$1.38 \quad(1.05,1.82)$

$1.67 \quad(0.88,3.18)$

0.740

$(0.60,5.67)$

$(0.59,2.20)$

1.14

$(1.00,3.42)$

1.85

$(0.74,1.70)$

1.12

0.947

$1.23 \quad(0.92,1.64)$

$1.91 \quad(1.00,3.62)$

0.788

1.44

$(1.07,1.95)$

1.26

$(0.72,2.21)$

0.339

$1.59 \quad(1.05,2.41)$

$1.22 \quad(0.89,1.66)$

0.118

$1.86 \quad(1.15,3.02)$

$1.24 \quad(0.93,1.65)$

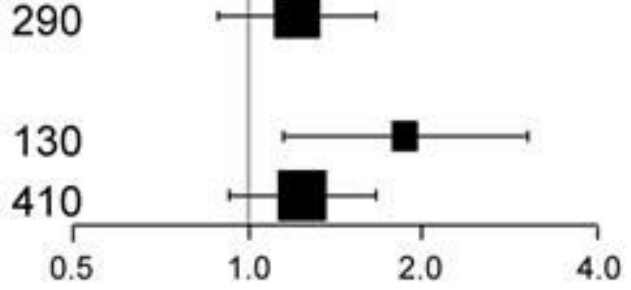

Figure 3

Stratified analysis based on clinicopathologic features (overall survival). AJCC, American Joint Committee on Cancer. In subgroup analyses, all identified confounding factors were adjusted except for the factor that the subgroup was based on. 
Subgroups

All

Sex

Female

Male

Age, years

$>=45,<60$

$>=60$

\section{Race}

White

Non-White

Tumor size, $\mathrm{mm}$

$<30$

$>=30,<50$

$>=50,<70$

$>=70$

Treatment modality

Non-surgical

Liver resection

Lynph node status

Negative

Positive

\section{AJCC-TNM stage}

I-II

III-IV

Year of diagnosis 2004-2009

2010-2015
No.

417

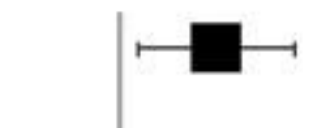

194

223

132

263
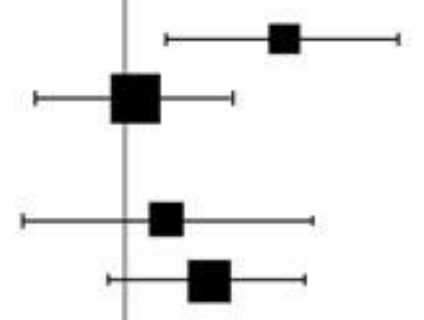

314

103

103

69

93

86

169
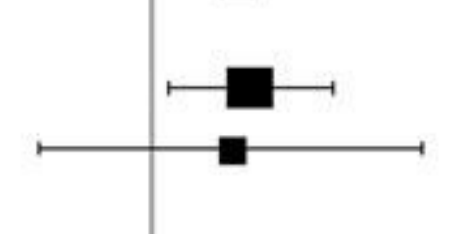

HR

1.46

$95 \% \mathrm{Cl}$

P-Interaction

$(1.08,1.97)$

1.86

1.05

$(1.19,2.93)$

$(0.71,1.54)$

1.19

$(0.68,2.09)$

1.39

$(0.95,2.02)$

1.47

$(1.06,2.02)$

1.37

$(0.65,2.87)$

0.615

0.268

0.052

0.929

$1.14 \quad(0.50,2.65)$

$1.07 \quad(0.52,2.21)$

$1.50 \quad(0.94,2.40)$

$1.23 \quad(0.89,1.71)$

$2.57 \quad(1.18,5.60)$

0.235

1.51

$(1.05,2.16)$

0.99

$(0.53,1.85)$

1.63

$(0.96,2.76)$

1.32

$(0.93,1.89)$

231

1.32

2.36

$(1.33,4.20)$

1.26

0.106

0.051

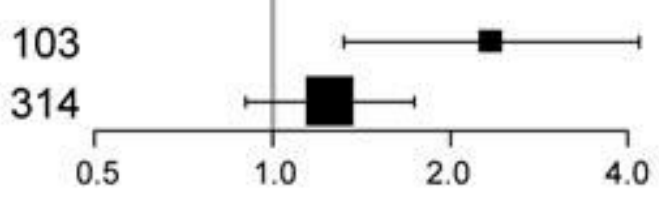

\section{Figure 4}

Stratified analysis based on clinicopathologic features (disease-specific survival). AJCC, American Joint Committee on Cancer. In subgroup analyses, all identified confounding factors were adjusted except for the factor that the subgroup was based on. 